\title{
Adverse Event Attribution Category
}

National Cancer Institute

\section{Source}

National Cancer Institute. Adverse Event Attribution Category. NCI Thesaurus. Code C53255.

A characteristic used to qualify the determination of whether an adverse event is related to medical product or procedure. 